\title{
Nanolevel Polishing Using MCF
}

\author{
Y. Matsuo ${ }^{1}$, K. Yamamoto ${ }^{2}$, K. Shimada ${ }^{3}$ \\ ${ }^{1,2}$ FDK CORPORATION, R\&D , 2281 Washizu, Kosai-shi, Shizuoka 431-0495, Japan \\ ${ }^{3}$ FUKUSHIMA University Faculty of Symbiotic Systems Science., 1 Kanayagawa, Fukushima \\ ${ }^{1}$ Fax: 81-53-575-2532, e-mail: matsuo@fdk.co.jp
}

\begin{abstract}
Recently, manufacturing of high tolerance with promoting downsizing of various electronic components is required for lighter, thinner, shorter, and smaller communication equipments and electronics products using cellular phone and digital camera. In these circumstances, new type mirror polishing technology has been developed in order to polish nm-order for surface of ceramics, metal, and plastics. This technology can be polished high accuracy as follows: (1) acrylic resin of irregularity shape, (2) acrylic resin of film. This paper describes the possibility of the surface treatment of acrylic resin of the three dimensional nano-level polishing using MCF(magnetic compound fluid).
\end{abstract}

Key words: MCF, nanolevel polishing, acrylic resin, soft magnetic material, light transmittance.

\section{INTRODUCTION}

With the recent growing demand for thinner, more lightweight communication equipment and electronic products such as cellular phones and digital cameras, ever-higher surface precision is required for micro-parts. To meet such needs, we have developed a technique to mirror-polish plastic and other material surfaces to a surface roughness of the order of several nanometers ${ }^{1)-6}$. This technique makes it possible to polish not only flat plastic materials but also plastic parts of complicated shape to high precision.

The present study, using the MCF (Magnetic Compound Fluid) paste, made basic consideration necessary to develop surface treatment methods to polish regularity and irregularity shape and a film-like acrylic resin surface to mirror finish in the order of nanometers. We found a technique to polish acrylic resin surfaces with roughness in the order of microns to mirror-finish in the order of nanometers.

\section{NANO-LEVEL POLISHING WITH THE MCF}

2.1 Magnetic polishing

A liquid containing iron, called the magnetic cluster $^{3)}$ and magnetism combine to make polishing possible without pressing a cutting tool strongly against an object. The magnetic cluster is a viscous liquid consisting of a mixture of iron powder of several micrometers, 10-nm magnetite, and an abrasive. This liquid has unique characteristics. With a magnet approached, the liquid forms many thin solid bars, which, as shown in Fig. 1(a), form brush-like fine branches. As these "brushes" sweep over rough surfaces, they can polish the surfaces in whatever shape to mirror finish in the order of nanometers. a) Appearance of MCF

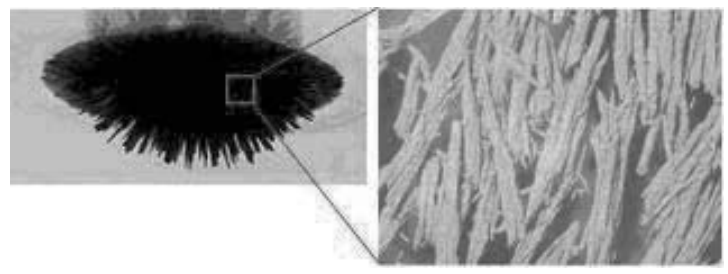

Fig.1, Appearance of MCF and internal cluster

2.2 Experimental equipment and polishing tools and paste

Fig. 2 shows the external view of a polishing system (3D-MNPS III, FDK Co.) used for our experiment. It can polish samples with the area of a maximum of 200 $\mathrm{mm} \times 200 \mathrm{~mm}$. The polishing tool moves up and down and to right and left with turning itself, and the frame moves in the longitudinal direction. This makes it possible to polish a sample surface into threedimensional shape. Fig. 3 illustrates the shape of the polishing tool, paste, and the polishing process. The polishing tool, as shown in a), consists of a permanent magnet at the distal end, the frame, and the shank part fastened to the rotating shaft. As shown in b), a required amount of paste is applied on a subject, c) the polishing tool is moved in three dimensions to polish the surface of a sample.

\section{EXPERIMENT AND DISCUSSIONS}

3.1 Preparing samples

A cutting tool (end mill) was set in place in the equipment shown in Fig. 2 (the head reciprocally moves in the X-direction with turning itself, and the frame reciprocally moves in the $\mathrm{Y}$ and Z-directions). The equipment machined the acrylic resin surface with this tool, and we obtained samples with initial roughness Ra of $0.6 \mu \mathrm{m}$ and Ry of $4.5 \mu \mathrm{m}$ (Ra: average roughness; Ry: maximum roughness : the maximum peak value of the wave shown in Fig. 5 - the minimum peak value). 
Then the tool was replaced by a polishing tool, made by adhering several grams of polishing paste (FDK Co.) to the $\mathrm{NdFeB}$ permanent magnet, and polishing was continued for $10 \mathrm{~min}$ at $500 \mathrm{rpm}$ of the polishing tool.

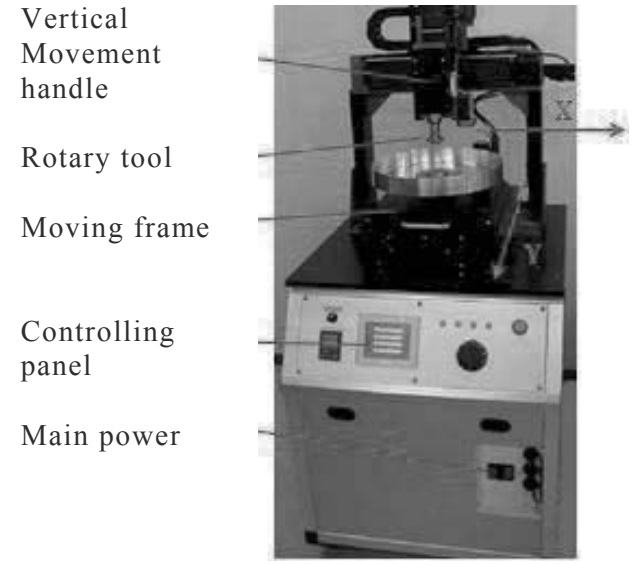

Fig.2, Photograph of the polishing machine(FDK 3D-MNPS III).
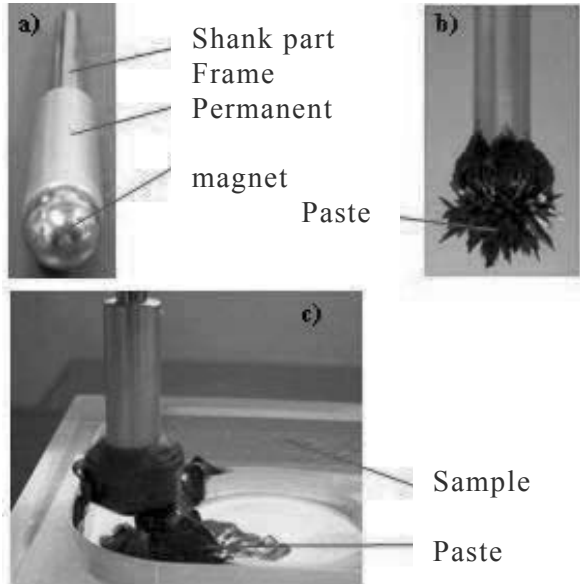

Fig.3, Polishing tool, paste and condition of processing.

3.2 Evaluation of the polished acrylic resin surface

The polished samples (thickness:10mm) were observed under the digital microscope (VH-Z500 or VH-Z100, Keyence Co.) for the surface condition. Then convex and concave surfaces and surface roughness were examined with a contact needle type surface roughness meter (P-10, Tenor Co.). The light transmittance of the polished acrylic resin was measured with a spectral photometer (U-3410, Hitachi Co.)

\subsection{Results and Discussions}

Fig. 4 shows the surfaces of samples before and after polishing observed under the digital microscope, and Fig. 5 surface roughness measurements taken with a contact needle type surface roughness meter as changes over a period of $2000 \mu \mathrm{m}$. The photos in Fig. 4 reveal well the process of surfaces' turning into the mirror as polishing proceeds. In the $0 \mathrm{~min}$ and $0.5 \mathrm{~min}$ samples roughness of several micrometers could be noted on the surfaces. The data in Fig. 5 indicate that Ra at 0 min was $0.57 \mu \mathrm{m}$ and that Ry was $4.45 \mu \mathrm{m}$. After polishing for 1 or $2 \mathrm{~min}$, roughness disappeared as shown in Fig. 4 with a pattern like the form of lines appearing instead. As shown in Fig. 5, polishing for $2 \mathrm{~min}$ almost flattens the waveform, lowering Ra to $0.03 \mu \mathrm{m}$ and Ry to $0.28 \mu \mathrm{m}$. With polishing continued for 5 and $10 \mathrm{~min}$, the form of lines disappeared as noted in Fig. 4. Polishing for $10 \mathrm{~min}$ flattens the waveform more. As presented in Fig $5 \mathrm{Ra}$ was $0.01 \mu \mathrm{m}$ and Ry $0.09 \mu \mathrm{m}$.

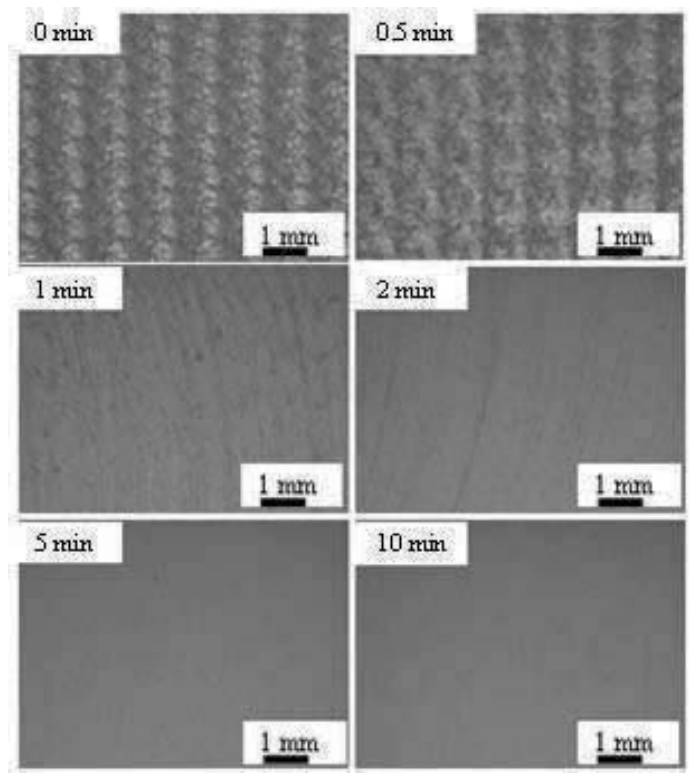

Fig.4, Photograph showing the change in surface roughness as a function of the polishing time.

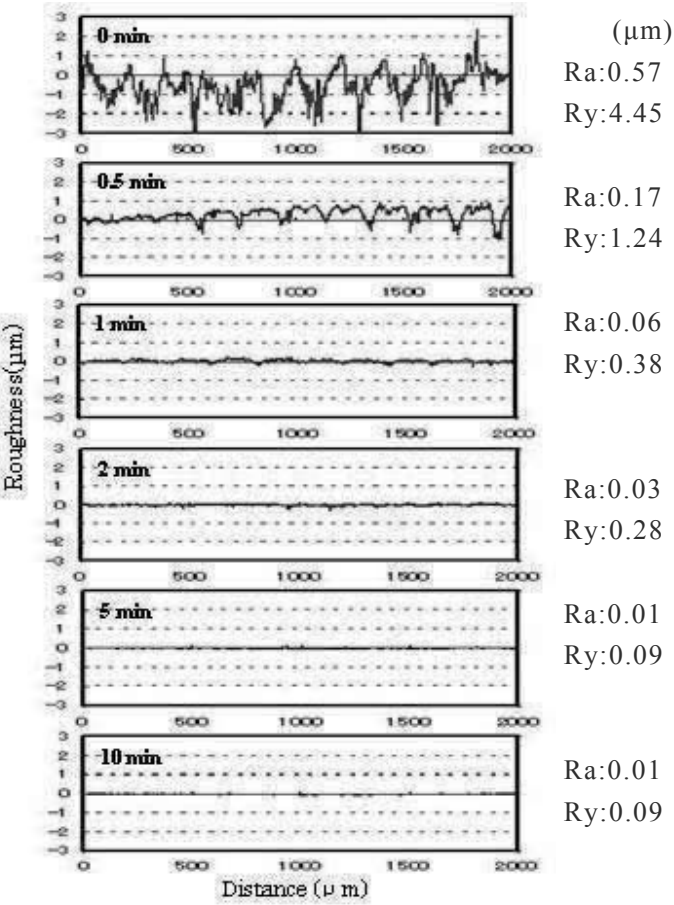

Fig.5, Effect of the polishing time on the surface roughness( $\mathrm{Ra}$ and $\mathrm{Ry}$ ) of acrylic resin. 
These results have confirmed that it is possible to polish acrylic resin surfaces to mirror finish from roughness of several micrometers to the order of 10 nanometers within a relatively short period of time. Fig. 6 shows a graph of light transmittance of the samples polished for 0 to $10 \mathrm{~min}$. With regard to the wavelengths around $800 \mathrm{~nm}$, polishing time 0 min gave rise to $20 \%$ of light transmittance, and $0.5 \mathrm{~min} 43 \%$ or so, whereas 1 min and $2 \mathrm{~min}$ increased it to $80 \%$. Polishing for 5 and 10 min were able to attain some $90 \%$.

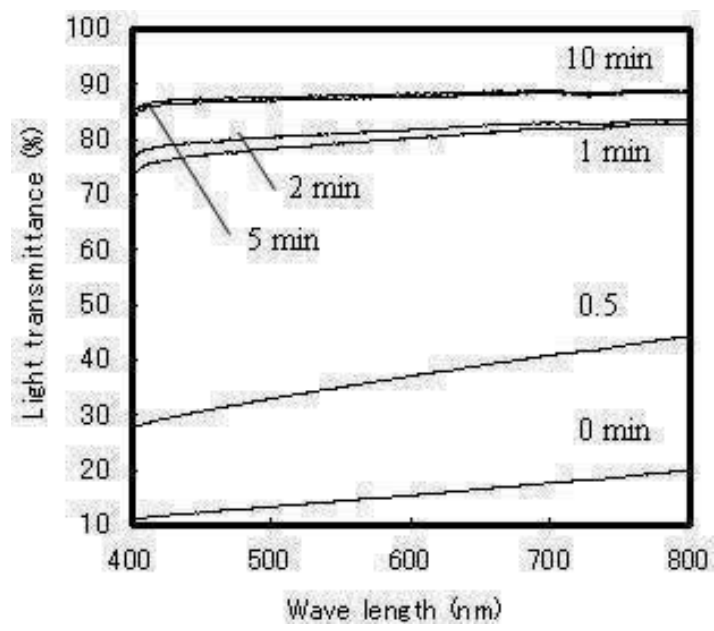

Fig.6, Effect of the polishing time on the light transmittance of acrylic resin

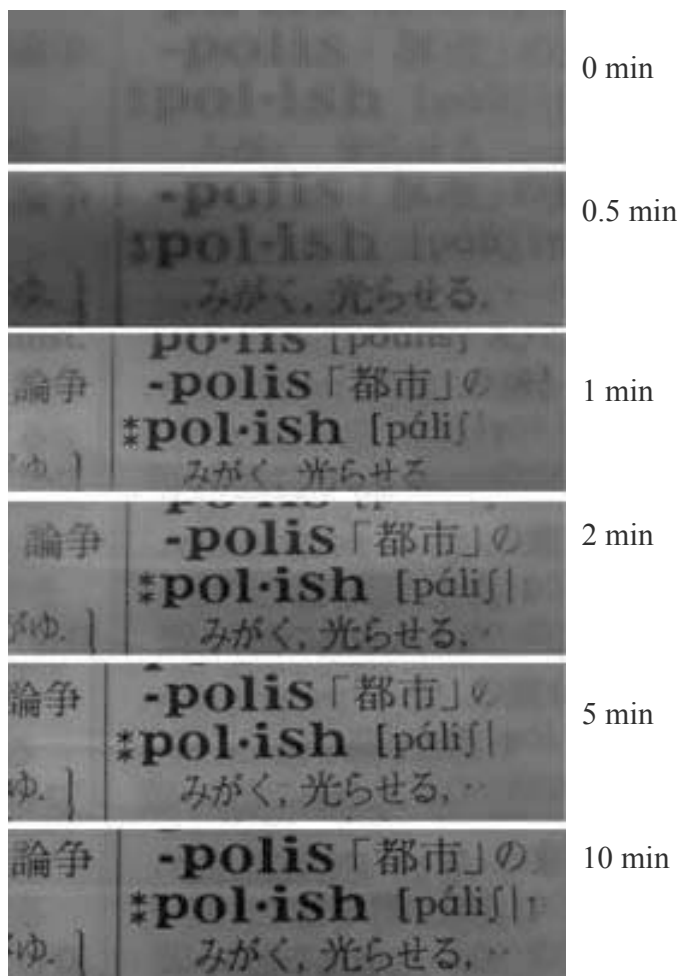

Fig.7, Photograph showing the clarity of acrylic resin as a function of the polishing time.
The light transmittance of commercially available acrylic resin is $93 \%$, which has been confirmed in the present study to be practically attained by polishing for 10 min. Fig. 7 shows photographs taken with a digital camera of letters on a dictionary page on which the samples polished for 0 to $10 \mathrm{~min}$ were placed to measure their clarity. Up to $0.5 \mathrm{~min}$ of polishing time the letters are unclear, whereas polishing for $1 \mathrm{~min}$ can create a clear plate. As polishing time further increases, letters even on the peripheral areas of the samples look clearer. This tendency corresponds well to the results in Figs. 4 through 6. Light transmittance at which letters are unclear is up to $40 \%$ or so, at which the resin surface has roughness of some $2 \mu \mathrm{m}$. This surface roughness, causing the irregular reflection of incident light, is considered to make the letters unclear. As light transmittance approaches $80 \%$ or so, great roughness on the resin surface disappears with a pattern like the form of lines having a height difference of $0.3 \mu \mathrm{m}$ appearing instead. Nevertheless the letters remain looking clear. When light transmittance reaches $90 \%$, the pattern like the form of lines on the resin surface disappears as well with the surface roughness height difference decreasing to some $0.09 \mu \mathrm{m}$, and the letters look clearer.

\subsection{Polishing Acrylic Films}

Similar polishing tests were conducted with commercially available acrylic films (thickness $125 \mu \mathrm{m}$ ). First the acrylic film surfaces were polished with sandpaper (\#1200) to obtain samples of initial roughness Ra $0.2 \mu \mathrm{m}$ and Ry $1.4 \mu \mathrm{m}$. Fig. 8 shows the photographs of the surfaces of the samples before and after polishing, taken under the digital microscope. Fig. 9 presents surface roughness measurements (changes over the period of $2000 \mu \mathrm{m}$ ) taken with a contact needle type surface roughness meter. The photographs in Fig. 8 indicates how a surface turns into a mirror with increase in polishing time. On the sample surface at time $0.1 \mathrm{~min}$ it is possible to identify roughness of several micrometers. After polishing for $5 \mathrm{~min}$, the waveform becomes practically flat as shown in Fig. 9 with $\mathrm{Ra}$ decreasing to $0.03 \mu \mathrm{m}$ and Ry to $0.24 \mu \mathrm{m}$. Continuing polishing further until time $21 \mathrm{~min}$, the pattern like the form of lines disappear as shown in Fig. 8. Ra at this point of time was $0.02 \mu \mathrm{m}$, and Ry $0.13 \mu \mathrm{m}$ as presented in Table I .The photographs in Fig. 10, taken with a digital camera, depict the clarity of the samples from polishing time 0 min to $21 \mathrm{~min}$. Up to polishing time 2 min letters on a dictionary page were unclear. They look clear after polishing for $5 \mathrm{~min}$. As polishing time increases further, letters even on the peripheral areas of the samples look clearer. This is considered to be attributable, as in the previous section, to the fact that the surface roughness causes the irregular reflection of incident light, consequently making the letters unclear.

\subsection{Conclusion}

Using MCF paste and an apparatus built anew, we studied polishing methods to work acrylic resin surfaces in flat and convex and concave shape to the order of nanometers. The results can be summarized as follows. 1) We polished acrylic resin and revealed the relationship between polishing and the surface condition, light transmittance, and clarity of the 
polished resin.

2) We could demonstrate that the present system was able to polish the flat and convex and concave surfaces of acrylic resin to the smoothness in the order of nanometers.

3) The present system is very effective in polishing acrylic resin in wide use for various products to the mirror surface in the order of nanometers. It will be hoped for as a surface treatment method for resin parts which are expected to be used more and more in the future.
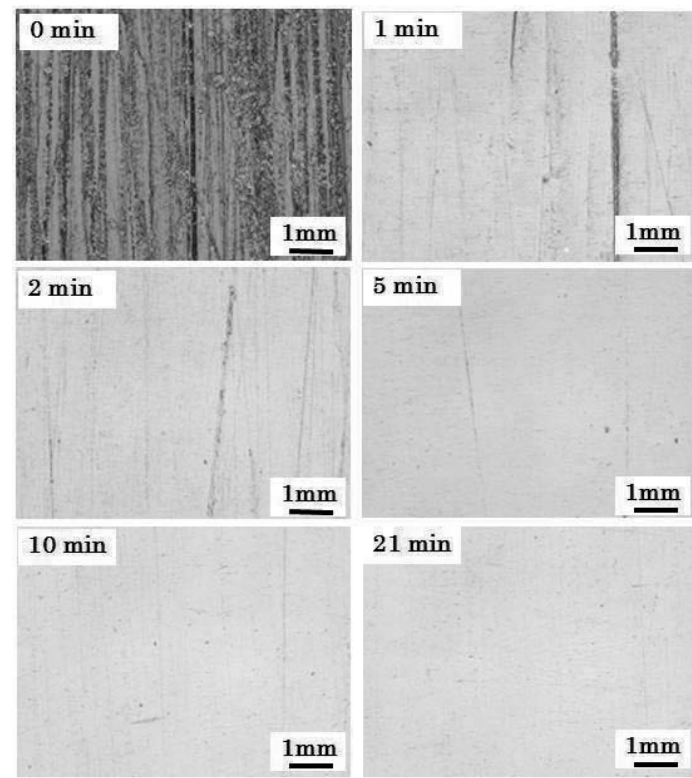

$21 \mathrm{~min}$

mm

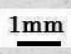

Fig.8, Photograph showing the change in surface roughness as a function of the polishing time.
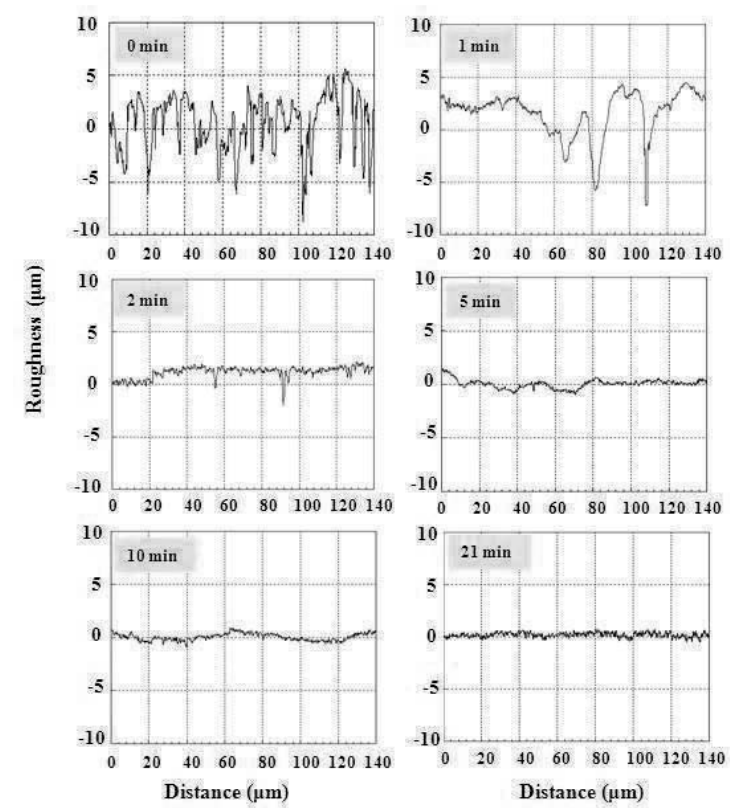

Fig.9, Effect of the polishing time on the surface roughness $(\mathrm{Ra})$ of acrylic films.
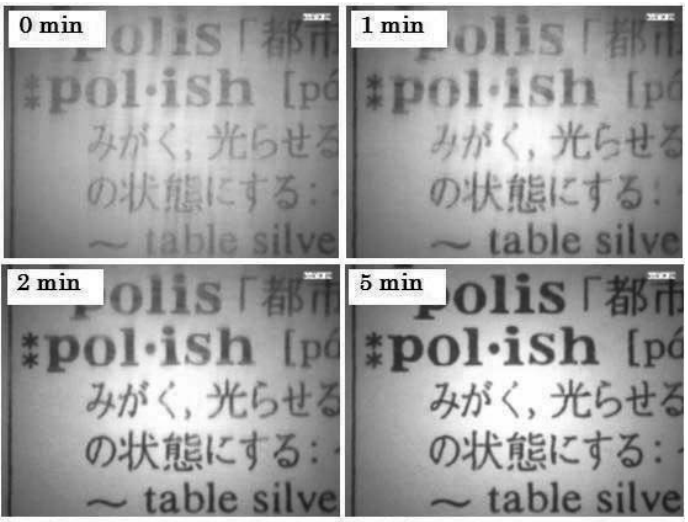

pol-ish [p

みがく, 光らせる

の状態にする：

$\sim$ table silve
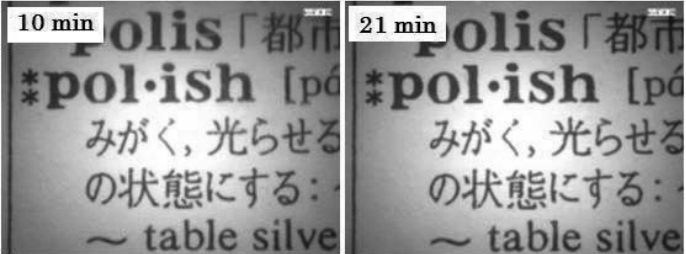

Fig. 10 Photograph showing the clarity of acrylic films as a function of the polishing time.

Table I . Effect of the polishing time on the surface roughness (Ra, Ry) of acrylic films.

\begin{tabular}{|cc|c|c|}
\hline \multicolumn{2}{|c|}{ Polishing time } & $\mathrm{Ra}(\mu \mathrm{m})$ & $\mathrm{Ry}(\mu \mathrm{m})$ \\
\hline 0 & $\mathrm{~min}$ & 0.21 & 1.44 \\
\hline 1 & " & 0.16 & 1.17 \\
\hline 2 & 0.04 & 0.41 \\
\hline 5 & 0.03 & 0.24 \\
\hline $10 \quad "$ & 0.03 & 0.19 \\
\hline 21 & 0.02 & 0.13 \\
\hline
\end{tabular}

3.6 References

[1]K.Shimada, Y.Akagami, T.Fujita, T.Miyazaki, S.Kamiyama, A.Shibayama,Journal of Magnetism and Ma gnetic Material s, Vol. 252 , 235-237 (2002).

[2] K.Shimada, Y.Akagami, S.Kamiyama, T.Fujita, T. Miyazaki, A. Shibayama,,Journal of Intelligent Materials Systems and Structures, Vol. 13, No. 7, 405-408. (2002).

[3] K.Shimada, Y.Wu, Y.Matsuo, K.Yamamoto, Journal of Material Processing Tech nology, Vol.162-163, 690-695 (2005).

[4] K.Shimada, Y.Matsuo, K.Yamamoto,

R.Hanamura, T.Sahashi, W.Yongbo, International Journal of A brasive tech nology, in submitting (2006).

[5] Y.Matsuo and K.Shimada, Japan Fine

Ceramics Association Rep ort, 24 No.2, 58-61 (2006).

[6] Y.Matsuo, K.Yamamoto, T.Nakamura, R.Hanamura and K. Shimada, J. Magn. Soc. Jpn.,Vol.31, No.1, 12-16 (2007).

(Received December 12, 2008 ; Accepted January 28, 2009) 